\title{
Epidemiological, life style, and occupational factors associated with lower limb varicose veins: a case control study
}

\author{
Shahira Elamrawy ${ }^{1}$ Iman Darwish ${ }^{1}$, Sameh Moustafa ${ }^{2}$, Noha Elshaer ${ }^{3 *}$ (D) and Nesma Ahmed ${ }^{4}$
}

\begin{abstract}
Background: Few data were documented about risk factors for lower limb varicose veins (LLW) among Egyptian population. Identifying modifiable risk factors is crucial to plan for prevention. The current research aims to study the epidemiological, life style, and occupational factors associated with LLW in a sample of Egyptian population.

Methods: A case control study was adopted. Cases with LLW $(n=150)$ were compared with controls $(n=$ 150). Data was collected using an interview questionnaire and clinical assessment. Data was analyzed using the univariate and multivariate logistic regression analyses.

Results: According to multivariate analysis among all participants $(n=300)$, the odds of LLW was 59.8 times greater for those who frequently lift heavy objects $(95 \% \mathrm{Cl}=6.01,584.36)$ and 6.95 times higher for those who drink < 5 cups of water) day $(95 \% \mathrm{Cl}=2.78,17.33)$. Moreover, it was 4.27 times greater for those who infrequently/never consume fiber-rich foods $(95 \% \mathrm{Cl}=1.95,9.37)$ and 3.65 times greater for those who stand $>4 \mathrm{~h} /$ day $(95 \% \mathrm{Cl}=1.63,8.17)$. Additionally, odds of LLW was 3.34 times greater for those who report irregular defecation habit $(95 \% \mathrm{Cl}=1.68,6.60)$, and 2.86 times higher for those who sleep $<8 \mathrm{~h} /$ day $(95 \% \mathrm{Cl}=1.14,7.16)$, and 2.53 times higher for smokers compared with ex-smokers/nonsmokers $(95 \% \mathrm{Cl}=1.15,5.58)$. In addition, a standing posture at work was an independent predictor of LLW among ever employed participants $(n=234)$ in the current study $(\mathrm{OR}=3.10 ; 95 \% \mathrm{Cl}=1.02,9.38)$.

Conclusions: This study highlighted seven modifiable independent predictors of LLW mostly related to the life style, namely, frequent lifting of heavy objects, drinking $<5$ cups of water/day, infrequent/no consumption of fiber-rich food, standing more than $4 \mathrm{~h} /$ day, irregular defecation habit, sleeping less than $8 \mathrm{~h} /$ day, and smoking. These findings provide a basis to design an evidence-based low-cost strategy for prevention of LLW among Egyptian population.
\end{abstract}

Keywords: Epidemiological factors, Life style, Occupational factors, Varicose veins

\section{Introduction}

Chronic venous disease (CVD) is a prevalent condition that tends to worsen with age. Symptoms of CVD include leg pain, discomfort, and heaviness, whereas the clinical signs are varicose veins, edema, skin discoloration, lipodermatosclerosis, and in severe cases, venous

\footnotetext{
* Correspondence: noha.alshaaer@alexmed.edu.eg; elshaer.n@gmail.com ${ }^{3}$ Industrial Medicine and Occupational Health, Community Medicine Department, Faculty of Medicine, Alexandria University, Champolion Street, El Azareeta, Alexandria 21131, Egypt

Full list of author information is available at the end of the article
}

ulceration [1]. Lower limb varicose veins (LLVV) may occur as a primary disease as a result of an internal biochemical or morphologic abnormality of the vein wall or as a result of secondary causes such as thrombosis or obstruction of deep veins, superficial thrombophlebitis, arteriovenous fistulas, and pressure on the abdominal veins during pregnancy or from a tumor [2]. Although LLVV seem to be simple cosmetic with benign nature problem, they can be a source of serious complications which can lead to missed work days, lower quality of life, and even loss of a limb or life [3].

\section{Springer Open}

() The Author(s). 2021 Open Access This article is licensed under a Creative Commons Attribution 4.0 International License, which permits use, sharing, adaptation, distribution and reproduction in any medium or format, as long as you give appropriate credit to the original author(s) and the source, provide a link to the Creative Commons licence, and indicate if changes were made. The images or other third party material in this article are included in the article's Creative Commons licence, unless indicated otherwise in a credit line to the material. If material is not included in the article's Creative Commons licence and your intended use is not permitted by statutory regulation or exceeds the permitted use, you will need to obtain permission directly from the copyright holder. To view a copy of this licence, visit http://creativecommons.org/licenses/by/4.0/. 
Globally, according to Davies review (2019), recent evidence supports the trends of varicose vein case rates of 51.9 cases per 1000 women and 39.4 cases per 1000 men. It also shows that the prevalence of CVD and varicose veins vary widely by region, though they are highest in Western countries [1]. A comprehensive review evaluated articles published in the English language over more than 55 years, and revealed prevalence estimates for varicose veins of $<1$ to $73 \%$ in women and 2 to $56 \%$ in men. The reported wide ranges in prevalence estimations reflect differences in the population distribution of risk factors, accuracy in application of diagnostic criteria, and the quality and availability of medical diagnostic and treatment resources [4]. In Egypt, Aly et al. crosssectional study (2020), conducted on women, found that $51.1 \%$ of women (aged 15-55 years old) had varicose veins [5].

Previous studies described the non-modifiable factors associated with LLVV such as positive family history of varices, increasing age, woman gender, and pregnancy $[4,6]$. On the other hand, the association between modifiable factors such as life style and occupational factors and the development of LLVV were debated. There is an ongoing controversy as to whether obesity is a primary risk factor for LLVV, or it acts as an aggravating factor only [7]. In addition, few studies examined the effect of estrogen therapy, hormone replacement therapy, physical activity, hypertension, diabetes mellitus, and traumatic injury to the extremities on $\operatorname{LLVV}[8,9]$.

Low dietary fiber intake, irregular defecation, and straining at initial bowel movements have been suggested as risk factors for LLVV, but the findings have been inconsistent $[4,6]$. In addition, effect of smoking habit and smoking intensity on the development of LLVV is debated [10-12]. Smoking may affect veins through oxidative stress, hypoxia (through carbon monoxide and nitric oxide fixation to hemoglobin), and endothelial damage; however, mechanisms leading to tissue damage are uncertain [13].

Occupational mechanical exposure in term of prolonged standing, sitting, walking, and lifting heavy objects have also been examined in a number of studies, of which some found a positive association with LLVV [4, 6], while other did not [8]. A study goes even so far to suggest a reverse relationship between prolonged sitting posture and prevalence of LLVVs, while confirming the impact of a prolonged standing posture of the occurrence of LLVV [4].

In Egypt, although venous diseases are one of the most common medical problems, there is few documented data about risk factors for LLVV among Egyptian population; those studies were done long time ago $[14,15]$. It was essential to update data; therefore, the current study was conducted to study the epidemiological, life style, and occupational factors associated with LLVV among cases attending vascular surgery clinic at the Alexandria Main University Hospital, Egypt, as determining the modifiable risk factors would be helpful in establishing an evidence-based strategy for prevention of LLVV among Egyptian population.

\section{Methods}

\subsection{Research design and setting}

A case control study was conducted at the vascular surgery outpatient clinic and ophthalmology outpatient clinic at the Alexandria Main University Hospital from January through May 2019. The field work was conducted over a 5-month period, two visits per week at each outpatient clinic.

\subsection{Participants}

\subsubsection{Selection of cases}

Cases attending the vascular surgery outpatient clinic during the period of the study were examined by a consultant of vascular surgery to identify cases meeting the case definition of LLVV. The case definition includes dilated, tortuous, and palpable subcutaneous veins typically larger than 3-4 $\mathrm{mm}$ in diameter mostly in the legs and ankles [16]. Cases of LLVV were diagnosed and classified using the Clinical, Etiologic, Anatomic, Pathophysiologic classification system of chronic venous insufficiently (CEAP) [17], which is widely accepted in the clinical and scientific communities. The classification was developed in an effort to incorporate use of duplex scanning in the diagnosis, and standardize evaluation for comparison of outcomes across clinical studies. CEAP includes clinical symptoms such as pain, presence of varicose veins, edema, hyperpigmentation, and ulcer. It also considers the etiology (primary or secondary), anatomic distribution and position, pathogenic mechanism (venous reflux, obstruction, or both), and produces a score based on the severity of the disease [17]. During the study period, a total of 168 cases meeting the diagnostic criteria were examined, of whom 150 agreed to participate in the study.

\subsubsection{Selection of controls}

An equal number of controls $(n=150)$ was selected from the ophthalmology outpatient clinic of the same hospital. The same procedure (CEAP) was used to exclude the presence of LLVV by the same consultant of vascular surgery. In the current study, patients with past history of thrombosis, or refused to participate in the study were excluded.

\subsubsection{Power analysis}

A power analysis was conducted using the Open Source Epidemiologic Statistics for Public Health (OpenEpi) [18] 
to ensure that the number of identified cases will detect a difference between cases and controls. The power analysis showed that enrolling 150 cases of LLVVs and 150 controls is capable to detect the least difference in the probability of exposure between cases and controls of $14 \%$ in respect to major risk factors, with an expected odds ratio of 2.2 at a power of $81.36 \%$ and confidence level of 0.95 ( $\alpha$ $=0.05)$.

\subsection{Research tools}

Data was collected from cases and controls using a predesigned and pre-tested interview questionnaire and clinical examination.

\subsubsection{Interview questionnaire was conducted to collect the following data}

2.3.1.1 Sociodemographic data Including participants' age, sex, rural/urban residence, education attainment, and marital status.

\subsubsection{Epidemiological and life style factors}

- Level of activity. Regular physical exercise (exercising for 150 min of moderate intensity aerobic physical activity throughout the week as running, walking, swimming, or spinning) [19]; frequency of lifting heavy objects/day; standing hours/day; sleeping hours/day; and sitting hours/day.

- Smoking habit. Inquiry was made into smoking habit and participants were classified into current smoker (still smoking at least one cigarette daily for as long as 1 year), ex-smoker (quit smoking for at least 6 months prior to the date of the study), and non-smoker (never smoked or smoked less than one pack per month or 20 packs in his/her whole life) [11]. Among smokers, smoking index (SI) was calculated by multiplying the number of cigarettes smoked per day by long life duration of smoking in years. Smokers were classified according to their SI into light smokers (SI < 200), moderate smokers (SI $=200-400)$, and heavy smokers $($ SI $>400)$ [20].

- Dietary habits and intestinal motility. Frequency of eating diet rich in fibers (fruit, dark green vegetables, orange vegetables, legumes, and whole grains); drinking water/day; regularity of defecation times/day; posture while defecation (sitting/squatting).

- Reproductive history of married women. Gravidity; parity; and the use of oral contraceptives (OCS).

- Family and medical history. Positive family history of varices ( $L L V V$, hemorrhoids, varicocele) among first degree relatives (parents, full siblings, or children) and second degree relatives (grandparents, grand-children, aunts, uncles, nephews, nieces, or half siblings); history of immobilization for 1-3 months; and history of leg trauma (sprains, strains, fractures, or joint dislocation).

\subsubsection{Occupational factors}

- Employment status. Participants were categorized into two categories: ever and never employed. The ever employed includes participants who are currently employed, retired, or those with past occupations. Ever employed participants were classified according to the International Standard Classification of Occupations (ISCO) [21].

- Duration of employment in years.

- Working hours/day and working hours/week.

- Work time (daytime or shift work)

- Nature of work. Participants were classified into white collar (performing professional, managerial, or administrative work), pink collar (related to customer interaction, entertainment, sales, or other service oriented work), and blue collar (job requires manual labor) [22].

- Posture at work. Spending more than half their lifetime working hours engaged in particular posture (standing, sitting, walking, and lifting heavy objects).

\subsection{Clinical examination was conducted to collect the following data: \\ 2.4.1 Anthropometric measurements}

Weight and height was obtained following standard procedures, and body mass index (BMI) was computed to classify participants into underweight $\left(\mathrm{BMI}<18 \mathrm{~kg} / \mathrm{m}^{2}\right)$, normal weight (BMI from 18.5 to $<25 \mathrm{~kg} / \mathrm{m}^{2}$ ), overweight (BMI from 25 to $<30 \mathrm{~kg} / \mathrm{m}^{2}$ ), and obese (BMI $\geq$ $\left.30 \mathrm{~kg} / \mathrm{m}^{2}\right)$ [23].

\subsubsection{Clinical examination of lower limbs}

Participants were subjected to a clinical examination of the lower limbs by a consultant of vascular surgery to ascertain or exclude the presence of LLVVs. Cases were classified into six categories following the CEAP system [17] including: $C_{0}$, no visible or palpable signs of cardiovascular disease $(\mathrm{CVD}) ; \mathrm{C}_{1}$, telangiectasia or reticular veins; $C_{2}$, varicose vein $>4 \mathrm{~mm}$ in diameter; $C_{3}$, edema as a sequel of varicose vein; $\mathrm{C}_{4}$, skin changes (pigmentations, venous eczema, etc.); $C_{5}$, skin changes with healed ulcerations; and $C_{6}$, skin changes with active ulcerations [17].

\subsection{Statistical analysis}

The SPSS v.20 (IBM Corp. Released 2011. IBM SPSS Statistics for Mac, Armonk, NY, USA) was used for data entry and analysis. Data was described using number and percentages as well as mean and standard deviation. Univariate logistic regression analysis was done to 
compute the odds ratio (OR) and the associated 95\% confidence interval $(95 \% \mathrm{CI})$ to quantify the risk of LLVVs associated with the potential related factors.

Multivariate logistic regression analysis was conducted to model LLVVs as a function of sociodemographic, epidemiologic, life style, and occupational risk factors. As occupational risk factors were applicable only to ever employed participants $(n=234)$, two multivariate regression models were constructed. The first one was a stepwise multivariate logistic regression analysis including all participants $(n=300)$, in which the potential epidemiological and life style risk factors that were significant in univariate analysis were considered in addition to age, gender, employment status, and family history of varices. The second model was a stepwise model limited to the ever employed participants $(n=234)$ in which the aforementioned factors were considered in addition to the potential occupational risk factors to study their independent effect.

Significance of the obtained results was judged at the $5 \%$ level $(\alpha=0.05)$. The explained variance of logistic regression models was determined by the Nagelkerke's $\mathrm{R}^{2}$ and Hosmer and Lemeshow goodness-of-fit test. Significant factors in univariate analysis that include cells having a count less than 5 were excluded from the multivariate analyses to avoid distortion of the model.

\section{Results}

According to CEAP classification system, the majority of cases with LLVV were categorized as C2 $(72.0 \%, n=$ $108)$ and C3 $(28.0 \%, n=42)$. In addition, cases with LLVV reported symptoms such as pain $(96.0 \%, n=144)$, lower limb edema $(27.3 \%, n=41)$, while bleeding or ulcers were not reported. Among cases, $82.7 \%$ have received conservative treatment, $24.7 \%$ reported frequent leg raising to alleviate symptoms, and 14\% reported frequent wearing compression stoking.

Univariate analysis revealed insignificant differences in the age and sex distribution of cases and controls. The mean age of cases was $49.90 \pm 12.09$ years compared with $50.26 \pm 10.98$ years among controls $(p=0.78)$. However, cases were 4 times more likely to report never been to school or completed their basic education compared with controls $(\mathrm{OR}=4.07 ; 95 \% \mathrm{CI}=2.51,6.62)$ (Table 1$)$.

Cases of LLVVs were 45.34 times more likely to report lifting heavy objects $(\mathrm{OR}=45.34 ; 95 \% \mathrm{CI}=6.12,345.94)$. Cases were significantly more likely to report standing for more than 4 h daily $(\mathrm{OR}=6.95 ; 95 \% \mathrm{CI}=4.08,11.86)$ and to sleep less than $8 \mathrm{~h}$ per day $(\mathrm{OR}=5.51 ; 95 \% \mathrm{CI}=3.02$, 10.04). No excess risk was found between cases and neither controls in respect to exercising nor the number of hours spent sitting each day (Table 2).

An excess of smokers was encountered among cases of LLVV compared with controls $30.0 \%$ compared with
$18.0 \%)$ resulting in an estimated risk of $1.95(95 \% \mathrm{CI}=$ 1.13, 3.36). Smokers with LLVV were 6.27 times more likely to be moderate or heavy smokers $(95 \% \mathrm{CI}=1.70$, 23.16) and have a significantly higher smoking index $(\mathrm{OR}=1.006 ; 95 \% \mathrm{CI}=1.001,1.01)$ (Table 2).

Relative to controls, cases with LLVVs were significantly more likely to report never or infrequently consuming diet rich in fibers $(\mathrm{OR}=8.76 ; 95 \% \mathrm{CI}=5.16$, 14.86), drink less than 5 cups of water/day $(\mathrm{OR}=14.57$; $95 \% \mathrm{CI}=7.68,27.62)$, and have irregular defecation habit $(\mathrm{OR}=5.03 ; 95 \% \mathrm{CI}=3.07,8.24)$. Compared with controls, a significantly higher percentage of cases with LLVVs reported squatting posture during defecation (16.7\% compared to $1.3 \%$ ) and taking laxatives $(20.7 \%$ compared to $4.7 \%)$. Cases were 14 times more likely to squat during defecation $(\mathrm{OR}=14.80 ; 95 \% \mathrm{CI}=3.43$, 63.71) and 5 times more likely to take laxatives (OR $=5.32 ; 95 \% \mathrm{CI}=2.26,12.51)$. Cases with LLVV were significantly more likely to be overweight or obese $\left(\mathrm{BMI} \geq 25 \mathrm{~kg} / \mathrm{m}^{2}\right)$ than controls $(\mathrm{OR}=2.57 ; 95 \% \mathrm{CI}$ = 1.09-6.08) (Table 2).

Reproductive factors were examined among married, widowed, and divorced women in the current study (cases $n=81$, controls $n=75$ ); $70.4 \%$ of women with LLVV reported having the disease after the first pregnancy. Women with LLVV were significantly more likely to have high gravidity ( $\geq 4$ times) $(\mathrm{OR}=4.2$; $95 \% \mathrm{CI}=1.97,8.95)$, and to have high parity $(\geq 4$ times $)(\mathrm{OR}=7.51 ; 95 \% \mathrm{CI}=2.91,19.33)$ than controls. Furthermore, women with LLVV tended to use OCs 5.20 times higher than controls $(95 \% \mathrm{CI}, 2.34$ 11.53). Among OCs users (cases $n=36$, controls $n=$ $10)$, the mean duration of use of OCs was significantly higher among cases with LLVV $(6.91 \pm 3.21)$ compared with controls $(3.30 \pm 2.83)(\mathrm{OR}=1.47$; $95 \% \mathrm{CI}=1.10,1.97)$ (Table 2).

Regarding family and medical history, cases with LLVV tended to have a positive family history of varices 1.73 times higher than controls $(95 \% \mathrm{CI}=1.06,2.82)$; they reported positive family history of LLVV, varicocele, and hemorrhoids $(87.9 \%, 6.9 \%$, and $5.2 \%$ respectively). Furthermore, cases with LLVV were significantly more likely to have a history of leg trauma than controls $(\mathrm{OR}=9.51$; $95 \% \mathrm{CI}=1.19,76.03$ ) (Table 2).

Cases and controls were comparable in respect to their employment status $(p=0.78)$. Among ever employed participants (cases $n=118$ and controls $n=116$ ); the majority of cases with LLVV were plant or machine operators (38.1\%) and craft workers $(27.1 \%)$, while the majority of controls were technicians/associated professionals (37.1\%) and service/sales workers (18.1\%) (Table 3).

Cases with LLVV were significantly more likely to work more than $8 \mathrm{~h}$ /day than controls $(\mathrm{OR}=2.82$; $95 \%$ 
Table 1 Sociodemographic characteristics of studied patients attending the vascular surgery and ophthalmology outpatient clinics at the Alexandria Main University Hospital, 2019, Egypt

\begin{tabular}{|c|c|c|c|c|c|c|}
\hline \multirow[t]{2}{*}{$\begin{array}{l}\text { Sociodemographic } \\
\text { characteristics }\end{array}$} & \multicolumn{2}{|c|}{$\begin{array}{l}\text { Cases } \\
(n=150)\end{array}$} & \multicolumn{2}{|c|}{$\begin{array}{l}\text { Controls } \\
(n=150)\end{array}$} & \multirow[t]{2}{*}{ OR $(95 \% \mathrm{Cl})$} & \multirow[t]{2}{*}{$P$ value } \\
\hline & No. & $\%$ & No. & $\%$ & & \\
\hline \multicolumn{7}{|l|}{ Gender } \\
\hline Male & 68 & 45.3 & 74 & 49.3 & \multirow[t]{2}{*}{$1.17(0.74,1.84)$} & \multirow[t]{2}{*}{0.48} \\
\hline Female & 82 & 54.7 & 76 & 50.7 & & \\
\hline \multicolumn{7}{|l|}{ Residence } \\
\hline Rural $^{\wedge}$ & 13 & 8.7 & 5 & 3.3 & \multirow[t]{2}{*}{$0.36(0.12,1.04)$} & \multirow[t]{2}{*}{$0.05^{*}$} \\
\hline Urban & 137 & 91.3 & 145 & 96.7 & & \\
\hline \multicolumn{7}{|l|}{ Level of education } \\
\hline Unschooling/basic education & 108 & 72.0 & 58 & 38.7 & \multirow[t]{2}{*}{$4.07(2.51,6.62)$} & \multirow[t]{2}{*}{$>0.001^{* * *}$} \\
\hline Secondary/higher education ${ }^{\wedge}$ & 42 & 28.0 & 92 & 61.3 & & \\
\hline \multicolumn{7}{|l|}{ Marital status } \\
\hline Never married ${ }^{\wedge}$ & 4 & 2.7 & 5 & 3.3 & 1 & \\
\hline Married & 111 & 74.0 & 121 & 80.7 & $1.14(0.30,4.37)$ & 0.84 \\
\hline Widowed & 19 & 12.7 & 16 & 10.7 & $1.48(0.34,6.47)$ & 0.59 \\
\hline Divorced & 16 & 10.7 & 8 & 5.3 & $2.50(052,11.9)$ & 0.25 \\
\hline \multicolumn{7}{|l|}{ Age (years) } \\
\hline Min-max & \multicolumn{2}{|c|}{$25-70$} & \multicolumn{2}{|c|}{$28-75$} & & \\
\hline Mean \pm SD & \multicolumn{2}{|c|}{$49.90 \pm 12.09$} & \multicolumn{2}{|c|}{$50.26 \pm 10.98$} & $0.99(0.98,1.02)$ & 0.78 \\
\hline
\end{tabular}

$\mathrm{CI}=1.56,5.11)$, and to work more than $48 \mathrm{~h} /$ week than controls $(\mathrm{OR}=2.53 ; 95 \% \mathrm{CI}=1.41,4.53)$. In addition, cases with LLVV tended to have shift work 65.93 times higher than controls $(\mathrm{OR}=65.93 ; 95 \% \mathrm{CI}=8.88$, 489.06), and to be a blue/pink collar 4 times higher than controls $(\mathrm{OR}=4.00 ; 95 \% \mathrm{CI}=2.28,7.04)$. Regarding posture at work, cases with LLVV were significantly more likely to stand at work for more than $4 \mathrm{~h}$ /working day than controls $(\mathrm{OR}=6.45 ; 95 \% \mathrm{CI}=3.47,11.98)$, and to sit at work for equal to or less than $4 \mathrm{~h}$ /working day than controls $(\mathrm{OR}=5.54 ; 95 \% \mathrm{CI}=3.05,10.06)$ (Table 3).

According to the stepwise logistic regression analysis conducted among all participants $(n=300)$ in the current study, the independent predictors of LLVVs were as follows: frequent lifting of heavy objects $(\mathrm{OR}=59.79 ; 95 \% \mathrm{CI}=6.01,584.36)$, drinking $<5$ cups of water/day $(\mathrm{OR}=6.95 ; 95 \% \mathrm{CI}=2.78$, 17.33), infrequent/no consumption of fiber-rich food $(\mathrm{OR}=4.27 ; 95 \% \mathrm{CI}=1.95,9.37)$, standing more than $4 \mathrm{~h}$ per day $(\mathrm{OR}=3.65 ; 95 \% \mathrm{CI}=1.63,8.17)$, irregular defecation habit $(\mathrm{OR}=3.34 ; 95 \% \mathrm{CI}=1.68,6.60)$, sleeping less than $8 \mathrm{~h}$ per day $(\mathrm{OR}=2.86 ; 95 \% \mathrm{CI}=$ $1.14,7.16)$, smoking $(\mathrm{OR}=2.53 ; 95 \% \mathrm{CI}=1.15$, $5.58)$, and age $(\mathrm{OR}=1.05 ; 95 \% \mathrm{CI}=1.02,1.09)$. Those factors were adjusted for gender, employment status, and family history of varices. This model was able to correctly classify $87.0 \%$ of cases and $81.0 \%$ of controls in the current study (Table 4).

Among ever employed participants $(n=234)$, the stepwise logistic regression model, which aimed at studying the independent effect of occupational risk factors, revealed that standing posture at work was an independent predictor of LLVV (OR $=3.10 ; 95 \% \mathrm{CI}=$ $1.02 ; 9.38)$, in addition to other epidemiological and life style predictors. This model was able to correctly classify $87.3 \%$ of the cases and $82.0 \%$ of the controls in the current study (Table 5).

\section{Discussion}

The current study identified important modifiable life style and occupational risk factors for the development of LLVV. Frequent lifting of heavy objects, drinking $<5$ cups of water/day, infrequent/no consumption of fiberrich food, standing more than $4 \mathrm{~h} /$ day, irregular defecation habit, sleeping less than $8 \mathrm{~h} /$ day, and smoking were independent predictors of LLVV. In addition, standing posture at work was found to be an independent occupational risk factor for LLVV among ever employed participants. 
Table 2 Epidemiological and life style factors associated with lower limbs varicose veins (LLW)

\begin{tabular}{|c|c|c|c|c|c|c|}
\hline \multirow[t]{2}{*}{ Epidemiological and life style factors } & \multicolumn{2}{|c|}{$\begin{array}{l}\text { Cases } \\
(n=150)\end{array}$} & \multicolumn{2}{|c|}{$\begin{array}{l}\text { Controls } \\
(n=150)\end{array}$} & \multirow[t]{2}{*}{ OR $(95 \% \mathrm{Cl})$} & \multirow[t]{2}{*}{$P$ value } \\
\hline & No. & $\%$ & No. & $\%$ & & \\
\hline \multicolumn{7}{|l|}{ Level of activity } \\
\hline \multicolumn{7}{|l|}{ Exercising } \\
\hline Yes (regular/irregular) $)^{\& \wedge}$ & 27 & 18.0 & 29 & 19.3 & $1.09(0.61,1.95)$ & 0.76 \\
\hline No & 123 & 82.0 & 121 & 80.7 & & \\
\hline \multicolumn{7}{|l|}{ Lifting heavy objects (frequency/day) } \\
\hline Frequent/very frequent $\$$ & 35 & 23.3 & 1 & 0.7 & $45.34(6.12,345.94)$ & $>0.001^{* * *}$ \\
\hline Occasional/rare/never^ & 115 & 76.7 & 149 & 99.3 & & \\
\hline \multicolumn{7}{|l|}{ Standing hours/day } \\
\hline$>4$ h/day & 89 & 59.3 & 26 & 17.3 & $6.95(4.08,11.86)$ & $>0.001^{* * *}$ \\
\hline$\leq 4 \mathrm{~h} /$ day^ & 61 & 40.7 & 124 & 82.7 & & \\
\hline \multicolumn{7}{|l|}{ Sleeping hours/day } \\
\hline$<8$ h/day & 62 & 41.3 & 17 & 11.3 & $5.51(3.02,10.04)$ & $>0.001^{* * *}$ \\
\hline$\geq 8$ h/day^ & 88 & 58.7 & 133 & 88.7 & & \\
\hline \multicolumn{7}{|l|}{ Sitting hours/day } \\
\hline$<8$ hours/day & 77 & 51.3 & 72 & 48.0 & $1.14(0.72,1.79)$ & 0.64 \\
\hline$\geq 8$ hours/day^ & 73 & 48.7 & 78 & 52.0 & & \\
\hline \multicolumn{7}{|l|}{ Anthropometric measurements } \\
\hline \multicolumn{7}{|l|}{ Body mass index (BMI) } \\
\hline Underweight and normal $(\mathrm{BMI}<25)^{\wedge}$ & 8 & 5.3 & 19 & 12.7 & $2.57(1.09,6.08)$ & $0.02^{*}$ \\
\hline Overweight and obese (BMI $\geq 25$ ) & 142 & 94.7 & 131 & 87.3 & & \\
\hline Min-max & 21.60 & & 21.48 & & & \\
\hline Mean \pm SD & 31.19 & & 27.6 & & $1.32(1.22,1.44)$ & $>0.001^{* * *}$ \\
\hline \multicolumn{7}{|l|}{ Smoking } \\
\hline \multicolumn{7}{|l|}{ Smoking status } \\
\hline Smoker & 45 & 30.0 & 27 & 18.0 & $1.95(1.13,3.36)$ & $0.01^{*}$ \\
\hline Ex-smoker/non-smoker ${ }^{\wedge}$ & 105 & 70.0 & 123 & 82.0 & & \\
\hline \multicolumn{7}{|l|}{ Smoking intensity ${ }^{\#}$} \\
\hline Light smoker^ & 34 & 63.0 & 32 & 91.4 & $6.27(1.70,23.16)$ & $>0.01^{* *}$ \\
\hline Moderate/heavy smoker & 20 & 37.0 & 3 & 8.6 & & \\
\hline \multicolumn{7}{|l|}{ Smoking index (SI) } \\
\hline Min-max & $20-50$ & & $25-3$ & & & \\
\hline Mean \pm SD & 188.5 & & 141. & & $1.006(1.001,1.01)$ & $0.02^{*}$ \\
\hline \multicolumn{7}{|l|}{ Dietary habits and intestinal motility } \\
\hline \multicolumn{7}{|l|}{ Consumption of diet rich in fibers } \\
\hline Occasional/rare/never & 103 & 68.7 & 30 & 20.0 & $8.76(5.16,14.86)$ & $>0.001^{* * *}$ \\
\hline Frequent/very frequent ${ }^{\wedge}$ & 47 & 31.3 & 120 & 80.0 & & \\
\hline \multicolumn{7}{|l|}{ Drinking water (cups/day) } \\
\hline$\geq 5$ cups/day & 136 & 90.7 & 60 & 40.0 & $14.57(7.68,27.62)$ & $>0.001^{* * *}$ \\
\hline$\geq 5$ cups/day & 14 & 9.3 & 90 & 60.0 & & \\
\hline \multicolumn{7}{|l|}{ Regularity of defecation } \\
\hline Irregular & 97 & 64.7 & 40 & 26.7 & $5.03(3.07,8.24)$ & $>0.001^{* * *}$ \\
\hline Regular^ & 53 & 35.3 & 110 & 73.3 & & \\
\hline
\end{tabular}


Table 2 Epidemiological and life style factors associated with lower limbs varicose veins (LLW) (Continued)

\begin{tabular}{|c|c|c|c|c|c|c|}
\hline \multirow[t]{2}{*}{ Epidemiological and life style factors } & \multicolumn{2}{|l|}{$\begin{array}{l}\text { Cases } \\
(n=150)\end{array}$} & \multicolumn{2}{|l|}{$\begin{array}{l}\text { Controls } \\
(n=150)\end{array}$} & \multirow[t]{2}{*}{ OR $(95 \% \mathrm{Cl})$} & \multirow[t]{2}{*}{$P$ value } \\
\hline & No. & $\%$ & No. & $\%$ & & \\
\hline \multicolumn{7}{|l|}{ Posture while defecation } \\
\hline Squatting & 25 & 16.7 & 2 & 1.3 & $14.80(3.43,63.71)$ & $>0.001^{* * *}$ \\
\hline Sitting ${ }^{\wedge}$ & 125 & 83.3 & 14 & 98.7 & & \\
\hline \multicolumn{7}{|l|}{ Taking laxatives } \\
\hline Yes & 31 & 20.7 & 7 & 4.7 & $5.32(2.26,12.51)$ & $>0.001^{* * *}$ \\
\hline $\mathrm{No}^{\wedge}$ & 119 & 79.3 & 143 & 95.3 & & \\
\hline \multicolumn{7}{|l|}{ Medical and family history } \\
\hline \multicolumn{7}{|l|}{ Family history of varices } \\
\hline Positive family history & 58 & 38.7 & 40 & 26.7 & $1.73(1.06,2.82)$ & $0.02^{*}$ \\
\hline Negative family history/not known^ & 92 & 61.3 & 110 & 73.3 & & \\
\hline \multicolumn{7}{|l|}{ Immobilization for 1-3 months } \\
\hline Yes & 13 & 8.7 & 0 & 0.0 & & \\
\hline $\mathrm{No}^{\wedge}$ & 137 & 91.3 & 150 & 100.0 & & \\
\hline \multicolumn{7}{|l|}{ Previous leg trauma } \\
\hline Yes & 9 & 6.0 & 1 & 0.7 & $9.51(1.19,76.03)$ & $0.01^{*}$ \\
\hline $\mathrm{No}^{\wedge}$ & 141 & 94.0 & 149 & 99.3 & & \\
\hline Reproductive factors & $(n=81)$ & $(n=75)$ & & & & \\
\hline \multicolumn{7}{|l|}{ Gravidity $^{a}$} \\
\hline$\geq 4$ & 36 & 44.4 & 12 & 16.0 & $4.20(1.97,8.95)$ & $>0.001^{* *}$ \\
\hline$<4^{\wedge}$ & 45 & 55.6 & 63 & 84.0 & & \\
\hline \multicolumn{7}{|l|}{ Parity $^{a}$} \\
\hline$\geq 4$ & 32 & 39.5 & 6 & 8.0 & $7.51(2.91,19.33)$ & $>0.001^{* * *}$ \\
\hline$<4^{\wedge}$ & 49 & 60.5 & 69 & 92.0 & & \\
\hline \multicolumn{7}{|l|}{ Use of OCs ${ }^{a}$} \\
\hline Yes (regular/irregular) & 36 & 44.4 & 10 & 13.2 & $5.20(2.34-11.53)$ & $>0.001^{* * *}$ \\
\hline $\mathrm{No}^{\wedge}$ & 45 & 55.6 & 65 & 86.8 & & \\
\hline \multicolumn{7}{|l|}{ Duration of OCs use (years) ${ }^{b}$} \\
\hline$<5$ years & 5 & 13.9 & 7 & 70.0 & $14.46(2.77,75.3)$ & $0.001^{* *}$ \\
\hline$\geq 5$ years & 31 & 86.1 & 3 & 30.0 & & \\
\hline Min-max & $1-12$ & & $1-10$ & & & \\
\hline Mean \pm SD & $6.91 \pm 3.21$ & & $3.30 \pm 2.83$ & & $1.47(1.10,1.97)$ & $>0.01^{* *}$ \\
\hline
\end{tabular}

Abbreviations: SI smoking index, SD standard deviation, $O R$ odds ratio, $C l$ confidence interval, $O C$ s oral contraceptive pills

${ }^{\wedge}$ Reference category

${ }^{\#}$ Among smokers (cases $n=54$, controls $\left.n=35\right)$, light smokers $(S I<200)$, moderate/heavy smokers $(\mathrm{SI} \geq 200)$

Where frequent is $\geq 5$ times per week

\& Regular exercise defined as $150 \mathrm{~min}$ of moderate intensity aerobic physical activity per week

aNumber of women excluding single women (cases $n=81$, controls $n=75$ )

${ }^{\mathrm{b}}$ Number of women using OCs (cases $n=36$, controls $n=10$ )

${ }^{*} p \leq 0.05$

${ }^{* *} p>0.01$

$* * * p>0.001$

Age was found to be an independent predictor of LLVV in the current study; an effect that was masked by other factors in univariate analysis, whereas gender and family history of varices were not associated with risk of LLVV. Similarly, several studies revealed an association between increasing age and varicose veins [10-12, 24, 25], no sex-dependent difference in LLVV, and a negative relation between family history and varicose veins [12]. On the contrary, in Ziegler et al. study, age was not a risk factor for varicose veins [26]. Also, some studies 
Table 3 Occupational factors associated with lower limbs varicose veins (LLW)

\begin{tabular}{|c|c|c|c|c|c|c|}
\hline \multirow[t]{2}{*}{ Occupational factors } & \multicolumn{2}{|c|}{ Cases } & \multicolumn{2}{|c|}{ Controls } & \multirow[t]{2}{*}{ OR $(95 \% \mathrm{Cl})$} & \multirow[t]{2}{*}{$P$ value } \\
\hline & No. & $\%$ & No. & $\%$ & & \\
\hline Employment status & \multicolumn{2}{|c|}{$(n=150)$} & \multicolumn{2}{|c|}{$(n=150)$} & & \\
\hline Never employed & 32 & 21.3 & 34 & 22.7 & $1.08(0.62,1.86)$ & 0.78 \\
\hline Ever employed (currently/previously) & 118 & 78.7 & 116 & 77.3 & & \\
\hline Among ever employed & \multicolumn{2}{|c|}{$(n=118)$} & \multicolumn{2}{|c|}{$(n=116)$} & & \\
\hline \multicolumn{7}{|l|}{ Duration of employment (years) } \\
\hline Min-max & \multicolumn{2}{|c|}{$2-50$} & \multicolumn{2}{|c|}{$2-50$} & & \\
\hline Mean \pm SD & \multicolumn{2}{|c|}{$23.55 \pm 13.70$} & \multicolumn{2}{|c|}{$24.50 \pm 14.09$} & $0.99(0.98,1.01)$ & 0.60 \\
\hline \multicolumn{7}{|l|}{ ISCO classification"\# } \\
\hline Professionals & 3 & 2.5 & 22 & 19.0 & 1 & \\
\hline Technicians and associated professionals & 24 & 20.3 & 43 & 37.1 & $0.27(0.01,4.00)$ & 0.34 \\
\hline Service and sales workers & 10 & 8.5 & 21 & 18.1 & $1.11(0.09,12.96)$ & 0.93 \\
\hline Skilled agricultural and fishery workers & 3 & 2.5 & 2 & 1.7 & $0.95(0.07,11.78)$ & 0.97 \\
\hline Craft and related trade workers & 32 & 27.1 & 8 & 6.9 & $3.00(0.15,59.89)$ & 0.47 \\
\hline Plant and machine operators & 45 & 38.1 & 18 & 15.5 & $8.00(0.64,99.66)$ & 0.10 \\
\hline Elementary occupations & 1 & 0.8 & 2 & 1.7 & $5.00(0.42,58.63)$ & 0.20 \\
\hline \multicolumn{7}{|l|}{ Working hours/day" } \\
\hline Working > 8 h/day & 47 & 39.8 & 22 & 19.0 & $2.82(1.56,5.11)$ & $>0.001^{* * *}$ \\
\hline Working $\leq 8 \mathrm{~h} /$ day $^{\wedge}$ & 71 & 60.2 & 94 & 81.0 & & \\
\hline \multicolumn{7}{|l|}{ Working hours/week } \\
\hline Working $>48 \mathrm{~h} /$ week & 47 & 39.8 & 24 & 20.7 & $2.53(1.41,4.53)$ & $>0.01^{* *}$ \\
\hline Working $\leq 48$ h/week & 71 & 60.2 & 92 & 79.3 & & \\
\hline \multicolumn{7}{|l|}{ Work time $e^{\#}$} \\
\hline Day work^ & 75 & 63.6 & 115 & 99.1 & $65.93(8.8,489.1)$ & $0.001^{* *}$ \\
\hline Shift work & 43 & 36.4 & 1 & 0.9 & & \\
\hline \multicolumn{7}{|l|}{ Nature of work ${ }^{\#}$} \\
\hline Blue/pink collar & 91 & 77.1 & 53 & 45.7 & $4.00(2.28,7.04)$ & $>0.001^{* * *}$ \\
\hline White collar ${ }^{\wedge}$ & 27 & 22.9 & 63 & 54.3 & & \\
\hline \multicolumn{7}{|l|}{ Posture at work ${ }^{\#}$} \\
\hline Standing & 66 & 55.9 & 18 & 15.5 & $6.91(3.71,12.84)$ & $>0.001^{* * *}$ \\
\hline Sitting ${ }^{\wedge}$ & 52 & 44.1 & 98 & 84.5 & & \\
\hline \multicolumn{7}{|l|}{ Sitting hours/working day ${ }^{\#}$} \\
\hline Sitting $\leq 4 \mathrm{~h} /$ working day & 65 & 55.1 & 21 & 18.1 & $5.54(3.05,10.06)$ & $>0.001^{* * *}$ \\
\hline Sitting $<4 \mathrm{~h} /$ working day ${ }^{\wedge}$ & 53 & 44.9 & 95 & 81.9 & & \\
\hline \multicolumn{7}{|l|}{ Standing hours/working day } \\
\hline Standing $<4$ h/working day & 64 & 54.2 & 18 & 15.5 & $6.45(3.47,11.98)$ & $>0.001^{* * *}$ \\
\hline Standing $>4$ h/working day ${ }^{\wedge}$ & 54 & 45.8 & 98 & 84.5 & & \\
\hline \multicolumn{7}{|l|}{ 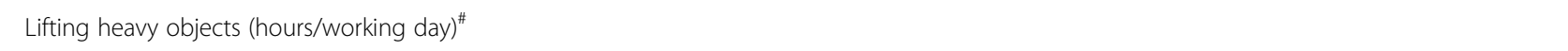 } \\
\hline$\geq 2$ h/working day & 7 & 5.9 & 1 & 0.9 & $7.25(0.87,59.90)$ & 0.06 \\
\hline$<2$ h/working day & 111 & 94.1 & 115 & 99.1 & & \\
\hline
\end{tabular}

ISCO International Standard Classification of Occupations, SD standard deviation, $\mathrm{Cl}$ confidence interval, OR odds ratio

${ }^{\wedge}$ Reference category

\#Number of participants currently/previously employed (cases $=118$, controls $=116$ )

${ }^{* *} p>0.01$

${ }_{* * *} p>0.001$ 
reported association between positive family history and varicose veins [6, 27]; the results of studies must be interpreted with caution, as varicose veins are a common problem, thus, a large proportion of study subjects would report a positive family history.

Besides, some studies revealed an association between female gender and varicose veins $[10,11,24,26]$. Different distribution of reproductive risk factors among women in different studies might lead to diverse results. Gravidity, parity, and use of OCs could independently increase the risk of LLVV among women compared with men, in some studies. Different findings may also be due to different study designs, sample size, and population characteristics.

The current study as well as previous studies reported the higher risk of LLVVs associated with high parity [4, $6,12,25]$ and the use of OCs [28]. Beebe-Dimmer et al. [4] attributed the adverse effects of pregnancy to the increase in blood volume as well as the increase in intraabdominal pressure and central venous return resulting from fetal growth and weight gain; the elevated pressure can result in valve failure and progression of varices. Also, the increase in the levels of relaxin, estrogen, and progesterone during pregnancy play a role in the development of varices. In contrast, other studies did not support the association of LLVVS with pregnancy [28] or the use of hormonal contraceptives [12, 26]. The variation in the effect of OCs between this study and that of Yun et al. study [12] could be attributed to the difference in the distribution of reproductive risk factors; all of the women in their study were working nurses and most of them were unmarried. In the current research, the small number of ever married women and those who ever used hormonal contraceptives precluded studying the independent effect of reproductive factors.
In the current study, never going to school or obtaining only basic education, which is a proxy for low socioeconomic status, was significantly associated with LLVV. This could be explained by the fact that level of education determines the nature of occupation (blue/ pink collar vs white collar) which directly affects the development of varices. Among ever employed participants in the current study, $65 \%$ of cases with LLVV were plant and machine operators and craft workers, while professionals represented $2.5 \%$ of cases. Likewise, in other studies, the majority of cases were manual laborers, farmers, house wives, nurses, utility workers, and cleaners $[24,26,29]$. This supports the observation that occupation involving violent muscular activity are at high risk for developing varicose veins. Hot and humid workplace conditions and socioeconomic may also be implicated [26].

Among ever employed participants in the current study, standing posture at work was found to be an independent predictor of LLVV. Most studies indicate that working in a position resulting in protracted orthostasis may increase the prevalence and severity of LLVV; a significantly higher prevalence of varicose veins was found in employees working in a prolonged standing posture $[6,24,26,30]$; while the lowest prevalence was found in medical technician assistants, secretaries, and scientific staff, since these professions have the shortest mean periods of standing at work [26].

Regarding physical activity, frequent lifting of heavy objects, standing for more than $4 \mathrm{~h} /$ day, and sleeping for less than $8 \mathrm{~h} /$ day, were found to be independent predictors of LLVV in the present study and in Tabatabaeifar et al. study [25]. Whereas no relation was found between regular physical exercise and the development of LLVV in the current study and in Yun et al. study [12]. On the

Table 4 Stepwise logistic regression analysis of the independent predictors of lower limb varicose veins (LLW) among all participants ( $n$ = 300)

\begin{tabular}{|c|c|c|c|c|}
\hline Independent predictors & Coefficient & Adjusted $\mathrm{OR}^{\dagger}$ & $95 \% \mathrm{Cl}$ & $P$ value \\
\hline Age & 0.05 & 1.05 & $(1.02,1.09)$ & $<0.01^{* *}$ \\
\hline Smoking & 0.93 & 2.53 & $(1.15,5.58)$ & $0.02^{*}$ \\
\hline Infrequent/no consumption of fiber-rich food & 1.45 & 4.27 & $(1.95,9.37)$ & $<0.001^{* * *}$ \\
\hline Drinking $<5$ cups of water/day & 1.94 & 6.95 & $(2.78,17.33)$ & $<0.001^{* * *}$ \\
\hline Irregular defecation habit & 1.20 & 3.34 & $(1.68,6.60)$ & $<0.01^{* *}$ \\
\hline Frequent lifting of heavy objects/day & 4.09 & 59.79 & $(6.01,584.36)$ & $<0.001^{* * *}$ \\
\hline Standing $>4 \mathrm{~h} /$ day & 1.29 & 3.65 & $(1.63,8.17)$ & $<0.01^{* *}$ \\
\hline Sleeping $<8$ h/day & 1.05 & 2.86 & $(1.14,7.16)$ & $0.02^{*}$ \\
\hline
\end{tabular}

Abbreviations: $O R$ odds ratio, $C l$ confidence interval

Model $X^{2}=200.91(p<0.001)$; Nagelkerke's $R^{2}=0.65 ;$ Cox and Snell $R^{2}=0.48$; Hosmer and Lemeshow $X^{2}=5.57(p=0.69)$

${ }^{\dagger} \mathrm{OR}$ adjusted for gender, employment status, family history of varices, and potential life style risk factors significant in univariate analysis (posture during

defecation, taking laxatives, and body mass index)

Occupational risk factors and significant factors that include cells having a count less than 5 were excluded from the regression model

${ }^{*} p<0.05$

${ }^{* *} p<0.01$

${ }^{* * *} p<0.001$ 
Table 5 Stepwise logistic regression analysis of the independent predictors of lower limb varicose veins (LLW) among ever employed participants $(n=234)$

\begin{tabular}{|c|c|c|c|c|}
\hline Independent predictors & Coefficient & Adjusted $\mathrm{OR}^{\dagger}$ & $95 \% \mathrm{Cl}$ & $P$ value \\
\hline Standing posture at work & 1.13 & 3.10 & $(1.02,9.38)$ & $0.04^{*}$ \\
\hline Age & 0.06 & 1.06 & $(1.02,1.10)$ & $<0.01^{* *}$ \\
\hline Frequent lifting of heavy objects/day & 3.63 & 37.59 & $(3.52,400.86)$ & $<0.01^{* *}$ \\
\hline Standing $>4$ h/day & 1.26 & 3.52 & $(1.20,10.33)$ & $0.02^{*}$ \\
\hline Infrequent/no consumption of fiber-rich food & 1.45 & 4.24 & $(1.70,10.62)$ & $<0.01^{* *}$ \\
\hline Drinking $<5$ cups of water/day & 2.24 & 9.42 & $(3.43,25.89)$ & $<0.001^{* * *}$ \\
\hline Irregular defecation habit & 1.87 & 6.46 & $(2.73,15.27)$ & $<0.001^{* * *}$ \\
\hline Taking laxatives & -1.63 & 0.20 & $(0.05,0.08)$ & $0.02^{*}$ \\
\hline
\end{tabular}

Abbreviations: $O R$ odds ratio, $\mathrm{Cl}$ confidence interval

Model $X^{2}=157.19(p<0.001)$; Nagelkerke's $R^{2}=0.65$; Cox and Snell $R^{2}=0.48$; Hosmer and Lemeshow $X^{2}=10.48(p=0.23)$

${ }^{\dagger}$ OR adjusted for gender, family history of varices, and potential occupational and life style risk factors significant in univariate analysis (working hours per week, nature of work, standing hours/working day, sitting hours/working day, body mass index, smoking, posture during defecation, and sleeping hours/day) Significant factors that include cells having a count less than 5 were excluded from the regression model

${ }^{*} p<0.05$

$*^{* *} p<0.01$

*** $p<0.001$

contrary, in other studies, regular exercising was found to be a protective factor [10,24]. The difference in findings might be due to different definitions of the regular exercising term in studies.

As regard dietary habits and intestinal motility, low dietary fiber intake, drinking less than 5 cups of water/ day, and irregular defecation were independent predictors of LLVV in the present study and in other studies $[4,24,31]$ which proposed that constipation and increased intra-abdominal pressure contributed to obstruction of venous return. People usually take laxatives to regulate their irregular bowel movement; this explains the change in findings in the present study, where taking laxatives was a risk factor for LLVV in univariate analysis, while in multivariate analysis, it had a protective effect.

Overweight or obesity (BMI $\geq 25$ ) was not a predictor of LLVV in the current study. In Seidel et al. study, the association between obesity and varicose veins was found in women but not in men [8]; however, in his study, there was an observed gender difference, besides, parity may act as a confounding factor due to the fact that parous women tend to have high average body weight [8]. In literature, the data on correlation between obesity and varicose veins is controversial; and whether it has an independent or an aggravating effect on the development of varicose veins is still debatable [7].

Smoking was an independent predictor of LLVV in the current study; smokers had 2.53 times greater risk to develop LLVV. Moreover, smoking intensity was significantly associated with LLVV; moderate/heavy smokers had 6.27 times greater risk to develop LLVV. Similarly, in a multicenter review and in other studies, the proportion of varicose veins cases with history of smoking was $19.4 \%$, and $45.6 \%$ [29], smokers had 1.8 times greater risk [30], and smoking pack-years significantly increases the odds of varicose veins by 1.12 [10]. It has been hypothesized that smoking leads to hypoxia, production of proinflammatory factors within the vessel wall, biochemical modifications on the venous endothelium that increases the vasomotor tonicity in the venous walls, and lengthening of scarring time which influence the trophic disorders associated with LLVV [30].

Few participants in the present study had a history of leg trauma and long immobilization which was significantly associated with LLVV in accordance with Abelyan et al. study [10]. In contrast, Yun et al. study found no significant association between leg injury and varicose veins [12]. The independent effect of those variables calls for further studies on a larger sample.

\subsection{Limitations of the study}

The current case control study (retrospective study) might be subjected to recall bias; cases with LLVVs would probably be more aware of the past medical and family events related to their conditions. Additionally, the relatively small number of ever married women limited studying the independent effect of reproductive factors.

\section{Conclusion}

The present study highlighted seven modifiable independent predictors of LLVV mostly related to the life style. These findings provide a foundation for planning an evidence-based low-cost strategy for prevention of LLVV among Egyptian population. Future studies are recommended to examine cause-effect relationship, and evaluate independent effect of reproductive factors on the development of LLVV. 


\section{Abbreviations}

BMI: Body mass index; CEAP: Clinical, Etiologic, Anatomic, Pathophysiologic; Cl: Confidence interval; CVD: Chronic venous disease; ISCO: International Standard Classification of Occupations; LLW: Lower limb varicose veins; OCs: Oral contraceptive pills; OR: Odds ratio; SD: Standard deviation; SI: Smoking index

\section{Acknowledgements}

Not applicable.

\section{Authors' contributions}

SE generated the research idea, and designed the work. ID designed the work, and revised the research article (manuscript) for submission. SM conducted the clinical examination of the lower limbs for all participants. NE carried out data analysis and interpretation, and drafted the research article. NA collected the data and revised the manuscript for submission. All authors have read and approved the manuscript.

\section{Funding}

Authors report that there was no funding source for the work or the preparation of the tools.

\section{Availability of data and materials}

Data and materials are available on reasonable request. Confidentiality and security of data and materials were insured through all stages of the study.

\section{Declarations}

\section{Ethics approval and consent to participate}

The study was approved by the Research Ethics Committee of AFM, University of Alexandria (the committee's reference number: not applicable). An informed written consent was obtained from each participant at the beginning of the study after explanation of the objectives of the study, procedures, and types of information to be obtained.

\section{Consent for publication}

Not applicable.

\section{Competing interests}

Authors declare no conflicts of interest. The research was not supported by any commercial source; no financial relationships with any organizations that might have an interest in the submitted work.

\section{Author details}

'Public Health, Preventive and Social Medicine, Community Medicine Department, Faculty of Medicine, Alexandria University, Alexandria, Egypt. ${ }^{2}$ Vascular Surgery Department, Faculty of Medicine, Alexandria University, Alexandria, Egypt. ${ }^{3}$ Industrial Medicine and Occupational Health, Community Medicine Department, Faculty of Medicine, Alexandria University, Champolion Street, El Azareeta, Alexandria 21131, Egypt. ${ }^{4}$ Ministry of Health, Alexandria, Egypt.

Received: 26 August 2020 Accepted: 11 May 2021

Published online: 06 July 2021

\section{References}

1. Davies AH. The seriousness of chronic venous disease: a review of realworld evidence. Adv Ther. 2019;36(S1):5-12.

2. Gloviczki P, Comerota AJ, Dalsing MC, Eklof BG, Gillespie DL, Gloviczki ML, et al. The care of patients with varicose veins and associated chronic venous diseases: clinical practice guidelines of the Society for Vascular Surgery and the American Venous Forum. J Vasc Surg. 2011;53(5):S2-48.

3. Raetz J, Wilson M, Collins K. Varicose veins: diagnosis and treatment. Am Fam Physician. 2019;99(11):682-8.

4. Beebe-Dimmer JL, Pfeifer JR, Engle JS, Schottenfeld D. The epidemiology of chronic venous insufficiency and varicose veins. Ann Epidemiol. 2005;15(3):175-84.

5. Aly SG, Wahdan MM, Ahmed DH, Ibrahim EF. Abd El- Hamid DM. Varicose veins: prevalence and associated risk factors among women of childbearing age attending a primary health care unit in Cairo, Egypt. Egypt Fam Med J. 2020;4(1):58-75.
6. Robertson L, Evans C, Fowkes F. Epidemiology of chronic venous disease. Phlebology. 2008;23(3):103-11.

7. Hirai MKN, Nakayama R. Prevalence and risk factors of varicose veins in Japanese women. Angiology. 1990;41(3):228-32.

8. Seidel AC, Belczak CE, Campos MB, Campos RB, Harada DS. The impact of obesity on venous insufficiency. Phlebology. 2015;30(7):475-80.

9. DA Brand FN, Abbott RD. The epidemiology of varicose veins: the Framingham study. Am J Prev Med. 1988;4(2):96-101.

10. Abelyan G, Abrahamyan L, Yenokyan G. A case-control study of risk factors of chronic venous ulceration in patients with varicose veins. Phlebology. 2018;33(1):60-7.

11. Lee AJ, Evans CJ, Allan PL, Ruckley CV, Fowkes FGR. Lifestyle factors and the risk of varicose veins: Edinburgh Vein Study. J Clin Epidemiol. 2003;56(2):171-9.

12. Yun MJ, Kim YK, Kang DM, Kim JE, Ha WC, Ky J, et al. A study on prevalence and risk factors for varicose veins in nurses at a university hospital. Safety Health Work. 2018;9(1):79-83.

13. Müller-Bühl U, Leutgeb R, Engeser P, Achankeng EN, Szecsenyi J, Laux G. Varicose veins are a risk factor for deep venous thrombosis in general practice patients. Vasa. 2012;41(5):360-5.

14. Darwish I. Some epidemiological features of cases having lower limb varicose veins attending the main university hospital in Alexandria. Master Thesis, Faculty of Medicine: Alexandria University; 1987.

15. Mekky S, Schilling R, Walford J. Varicose veins in women cotton workers. An epidemiological study in England and Egypt. Br Med J. 1969;2(5657):591-5.

16. Piazza G. Varicose veins. Circulation. 2014;130(7):582-7.

17. Eklöf B. CEAP classification and implications for investigations. Acta Chir Belg. 2006;106(6):654-8.

18. Dean AG, Sullivan KM, Soe MM. OpenEpi: open source epidemiologic statistics for public health, Version. www.OpenEpi.com, 2013

19. World Health Organization. Global strategy on diet, physical activity and health. WHO. [Internet] 2018. Available from: http://www/who/int/ dietphysicalactivity/pa/en

20. Lee Y, Shin M, Kweon S, Choi J, Rhee J, Ahn H, et al. Cumulative smoking exposure, duration of smoking cessation, and peripheral arterial disease in middle-aged and older Korean men. BMC Public Health. 2011;11(1):94.

21. International Labour Organization Office. The International Standard Classification of Occupations: introduction to occupational classifications. ILO. [Internet] 2018. [cited in 2020, April 2]. Available from: http://www.ilo. org/public/english/bureau/stat/isco/intro.htm.

22. Holland PJHR, Steen J. Human resource strategies and organizational structures for managing gold-collar workers. J Eur Ind Train. 2002;26(2-4):80.

23. Papadakis MA, Rabow MW. CURRENT medical diagnosis and treatment. Mc Graw Hill Education Lange 2018;57.

24. Sharif Nia H, Chan $\mathrm{YH}$, Haghdoost AA, Soleimani MA, Beheshti Z, Bahrami N. Varicose veins of the legs among nurses: occupational and demographic characteristics. Int J Nurs Pract. 2015;21(3):313-20.

25. Tabatabaeifar S, Frost P, Andersen JH, Jensen LD, Thomsen JF, Svendsen SW. Varicose veins in the lower extremities in relation to occupational mechanical exposures: a longitudinal study. Occup Environ Med. 2015;72(5): 330-7.

26. Ziegler SEG, Stoger R, Machula J, Rudiger $\mathrm{H}$. High prevalence of chronic venous disease in hospital employees. Wien. Klin. Wschr. 2003;575:9. Austria.

27. Bahk JW, Kim H, Jung-Choi K, Jung MC, Lee I. Relationship between prolonged standing and symptoms of varicose veins and nocturnal leg cramps among women and men. Ergonomics. 2012;55(2):133-9.

28. Robertson L, Evans C, Lee A, Allan P, Ruckley C, Fowkes F. Incidence and risk factors for venous reflux in the general population: Edinburgh Vein Study. Eur J Vasc Endovasc Surg. 2014;48(2):208-14.

29. Joseph N, Abhishai B, Thouseef MF, Devi U, Abna A, Juneja I. A multicenter review of epidemiology and management of varicose veins for national guidance. Ann Med Surg. 2016:8:21-7.

30. Gourgou S, Dedieu F, Sancho-Garnier H. Lower limb venous insufficiency and tobacco smoking: a case-control study. Am J Epidemiol. 2002;155(11): 1007-15.

31. Lee AJ, Evans CJ, Hau CM, Fowkes FG. Fiber intake, constipation, and risk of varicose veins in the general population: Edinburgh Vein Study. J Clin Epidemiol. 2001;54(4):423-9.

\section{Publisher's Note}

Springer Nature remains neutral with regard to jurisdictional claims in published maps and institutional affiliations. 